\title{
Safety and efficacy of enzyme replacement therapy in combination with hematopoietic stem cell transplantation in Hurler syndrome
}

Satkiran S. Grewal, $M D^{1}$, Robert Wynn, $M D, M R C P^{2}$, Jose E. Abdenur, $M D^{3}$, Barbara K. Burton, $M D^{4}$, Maged Gharib, $M D^{2}$, Claudia Haase, $M D^{5}$, Robert J. Hayashi, $M D^{6}$, Shalini Shenoy, $M D^{6}$, David Sillence, $M D^{7}$, George E. Tiller, $M D^{8}$, Martha E. Dudek ${ }^{8}$, Annet van Royen-Kerkhof, $M D^{9}$, James E. Wraith, $M D^{10}$, Paul Woodard, $M D^{11}$, Guy A. Young, $M D^{3}$, Nico Wulffraat, $M D, P h D^{9}$, Chester B. Whitley, $P h D, M D^{1}$, and Charles Peters, $M D^{1}$

\begin{abstract}
Purpose: Hurler syndrome is a debilitating genetic disease with a typical life span of 5 to 8 years. Early hematopoietic stem cell transplantation (HSCT) mitigates disease symptoms and improves survival. However, morbidity and mortality associated with HSCT can limit its success. We describe the initial experience with combined use of enzyme replacement therapy (ERT, laronidase) and HSCT in Hurler syndrome. Methods: Thirteen transplants were performed in 12 patients. ERT was given at a standard dose of $0.58 \mathrm{mg} / \mathrm{kg}$ per week. Transplant conditioning regimen and donor graft source were determined by institutional protocol. Results: The median age at initiation of ERT was 12 months (range, 8 to 18 months). The median duration of pre-HSCT ERT was 12 weeks (range, 4 to 28). All but 1 patient tested showed decrease in urinary GAG excretion during ERT. ERT infusion-related toxicity was limited to mild reactions. Development of antibodies to laronidase did not correlate with infusion reactions or responses in urinary GAG excretion. ERT was given for a median of 7 weeks (range, 3 to 20) after HSCT. After transplantation, eight patients demonstrated complete donor engraftment and four suffered graft failure. Two patients required ventilator support and three developed acute GVHD. Eleven of the 12 patients are surviving with a median follow-up of 3 months (range, 1 to 7 months). Conclusions: In children with Hurler syndrome, ERT with HSCT is feasible and well tolerated. Development of antibodies against exogenous enzyme does not appear to correlate with infusion reactions or response to ERT. A prospective study is needed to determine the effect of concomitant ERT on transplant outcomes. Genet Med 2005:7(2):143-146.
\end{abstract}

Key Words: Hurler syndrome, mucopolysaccharidosis, enzyme replacement therapy, laronidase, hematopoietic stem cell transplantation.

Mucopolysaccharidosis type I (MPS I) is caused by an inherited deficiency of the lysosomal enzyme $\alpha$-L-iduronidase, which results in accumulation of partially degraded glycosaminoglycans (GAGs) in lysosomes and their excretion in urine. ${ }^{1}$ Hurler syndrome (MPS IH) represents the most severe phenotype of MPS I and is characterized by

From the ${ }^{1}$ Department of Pediatrics, University of Minnesota, Minneapolis, Minnesota; ${ }^{2}$ Royal Manchester Children's Hospital, Manchester, United Kingdom; ${ }^{3}$ Children's Hospital of Orange County, Orange, California; ${ }^{4}$ Children's Memorial Hospital, Chicago, Illinois; ${ }^{5}$ Children's Hospital University, Jena, Germany; ${ }^{6}$ St. Louis Children's Hospital, St. Louis, Missouri; ${ }^{7}$ Children's Hospital at Westmead, Sydney, Australia; ${ }^{8}$ Division of Medical Genetics, Vanderbilt University Medical Center, Nashville, Tennessee; ${ }^{9}$ Wilhelmina Children's Hospital, Utrecht, the Netherlands; ${ }^{10}$ Willink Biochemical Genetics Unit, Manchester, UK; and ${ }^{11}$ St. Jude Children's Research Hospital, Memphis, Tennessee.

Satkiran S. Grewal, MD, Pediatric Blood and Marrow Transplantation, University of Minnesota, 420 Delaware St. SE., MMC 477, Minneapolis, MN, 55455.

Received: July 23, 2004.

Accepted: November 4, 2004.

DOI: 10.1097/01.GIM.0000154299.22120.6A progressive multisystem manifestations including obstructive airway disease, cardiac manifestations, hydrocephalus, neurocognitive decline, and dysostosis multiplex. ${ }^{1}$ Hematopoietic stem cell transplantation (HSCT) can reverse the airway obstruction, prevent certain aspects of the cardiac disease, stabilize learning ability, and increase longevity. ${ }^{2-4}$ However, morbidity and mortality inherent to HSCT limit its benefits. As a group, children with Hurler syndrome are particularly susceptible to pulmonary complications in the early period after HSCT.5,6

Enzyme replacement therapy (ERT) represents another viable therapeutic option in MPS I. ${ }^{7,8}$ Laronidase (recombinant human $\alpha$-L-iduronidase) infusions reduce abnormal and excessive GAG deposits in several tissues, resulting in decreases in hepatomegaly and urinary GAG excretion and improvements in upper airway obstruction as well as lung function tests.7,8 However, a limitation of intravenous ERT is its inability to cross the blood brain barrier'; hence, it is not predicted to help the central nervous system directly. 
As ERT can mitigate airway and pulmonary manifestations of MPS I, we hypothesized that ERT before and after HSCT would decrease transplant-related complications in Hurler children. We describe the initial multi-institution experience using ERT and HSCT combination therapy in Hurler syndrome.

\section{METHODS}

We received data from nine institutions on 12 HSCTs involving 11 children with Hurler syndrome. In addition, data on one patient was captured from an abstract. ${ }^{10}$ The diagnosis of Hurler syndrome was established by clinical features and deficient activity of leukocyte $\alpha$-L-iduronidase. Enzyme replacement therapy with laronidase was infused once a week at a standard dose of $0.58 \mathrm{mg} / \mathrm{kg}$. Preparative regimens for the transplant procedure were determined by the participating centers. Institutional review boards approved all treatment protocols.

\section{RESULTS}

Patient characteristics and transplant-related outcomes are summarized in Table 1.

\section{Enzyme replacement therapy}

Infusion-associated reactions were seen in two patients during the pre-HSCT infusion phase; these were limited to flushing and hives in one patient and fever with vomiting in another. The intensity of reactions did not increase with subsequent infusions. An additional patient had a single infusion-associated reaction only after HSCT (rash and hypotension), which did not recur. At baseline, titers of antibody against laronidase were negative in all five patients evaluated. Follow-up evaluations were available in three of these patients: two patients (patients 2 and 8) were subsequently tested for development of antibodies during ERT; both developed positive titers, but neither had infusionassociated reactions and both showed progressive decreases in urinary GAG excretion. The third patient (Patient 1), who did not develop any infusion-associated reactions, was subsequently evaluated for antibodies 12 weeks after HSCT and was found to have positive titers.

\section{Nontransplant outcomes}

Baseline (before initiation of ERT) urinary GAGs were elevated in all 10 patients tested. Follow-up measurements during therapy were performed in seven patients. During the preHSCT ERT phase, the urinary GAG concentration declined by a median of $40 \%$ (range, $30 \%-70 \%$ ) in six of the seven (the one exception was Patient 4). In three of these six patients, the levels of urinary GAG further declined to the normal range after HSCT.

Apnea/hypopnea index (by polysomnogram) or high-risk respiratory history (snoring, frequent respiratory infections, or

Table 1

Summary of patient, enzyme replacement, and transplant characteristics

\begin{tabular}{|c|c|c|c|c|c|c|c|c|c|c|c|c|}
\hline & \multicolumn{3}{|c|}{ Pre-HSCT } & \multicolumn{2}{|l|}{ HSCT } & \multicolumn{7}{|c|}{ Post-HSCT } \\
\hline & $\begin{array}{l}\text { Mutation } \\
\text { Analysis }\end{array}$ & $\operatorname{Age}^{a}$ & $\begin{array}{c}\text { Duration of ERT } \\
\text { before HSCT }\end{array}$ & $\begin{array}{l}\text { Conditioning } \\
\text { regimen for HSCT }\end{array}$ & $\begin{array}{c}\text { Donor } \\
\text { graft }\end{array}$ & $\begin{array}{c}\text { Follow- } \\
\text { up }\end{array}$ & $\begin{array}{c}\text { Duration } \\
\text { of ERT } \\
\text { after HSCT }\end{array}$ & $\begin{array}{l}\text { Vital } \\
\text { status }\end{array}$ & $\begin{array}{c}\text { Donor } \\
\text { engraftment }\end{array}$ & Acute GvHD & $\begin{array}{l}\text { Ventilator } \\
\text { support }\end{array}$ & $\begin{array}{l}\text { Pulmonary } \\
\text { hemorrhage }\end{array}$ \\
\hline 1. & ND & $18 \mathrm{mo}$ & 24 weeks & $\mathrm{Bu}, \mathrm{Cy}$ & R-BM & $3 \mathrm{mo}$ & 12 weeks & alive & complete & no & no & no \\
\hline 2. & ND & $9 \mathrm{mo}$ & 12 weeks & $\mathrm{Bu}, \mathrm{Cy}, \mathrm{Flu}$ & U-BM & $7 \mathrm{mo}$ & 4 weeks & alive & complete & Yes, grade II & Yes, for 12 days & no \\
\hline 3. & ND & $8 \mathrm{mo}$ & 8 weeks & $\begin{array}{r}{ }^{b} \text { Flu, Melphalan, } \\
\text { Campath, TLI }\end{array}$ & $\mathrm{R}-\mathrm{BM}$ & $1 \mathrm{mo}$ & 3 weeks & alive & complete & no & no & no \\
\hline $\begin{array}{l}4 \mathrm{a} \\
4 \mathrm{~b}\end{array}$ & W402X, W402X & $15 \mathrm{mo}$ & $\begin{array}{l}10 \text { weeks } \\
8 \text { weeks }\end{array}$ & $\begin{array}{l}{ }^{b} \mathrm{Flu}, \mathrm{Cy}, \mathrm{ATG} \\
\mathrm{Bu}, \mathrm{Cy}\end{array}$ & $\begin{array}{l}\text { UCB } \\
\text { UCB }\end{array}$ & $1 \mathrm{mo}$ & 4 weeks & Dead & $\begin{array}{l}\text { Failed } \\
\text { complete }\end{array}$ & $\begin{array}{l}\text { No } \\
\text { no }\end{array}$ & $\begin{array}{l}\text { no } \\
\text { Yes, till death }\end{array}$ & $\begin{array}{l}\text { no } \\
\text { Yes }\end{array}$ \\
\hline 5. & $\begin{array}{l}\text { W402X } \\
\text { W402X }\end{array}$ & $13 \mathrm{mo}$ & 6 weeks & $\mathrm{Bu}, \mathrm{Cy}, \mathrm{Flu}$ & R-PBSC & $6 \mathrm{mo}$ & 20 weeks & alive & complete & Yes, grade II & no & no \\
\hline 6. & $\mathrm{ND}$ & $14 \mathrm{mo}$ & 16 weeks & Bu, Cy, ATG & U-BM & $3 \mathrm{mo}$ & 8 weeks & alive & complete & yes & no & no \\
\hline 7. & $\begin{array}{l}\text { Q70X } \\
\text { W402X }\end{array}$ & $9 \mathrm{mo}$ & 12 weeks & $\begin{array}{l}{ }^{b} \text { Alemtuzumab, Flu, } \\
\text { Treosulfan }\end{array}$ & U-BM & $1 \mathrm{mo}$ & 12 weeks & alive & complete & no & no & no \\
\hline 8. & $\begin{array}{l}\text { W402X } \\
\text { W402X }\end{array}$ & $8 \mathrm{mo}$ & 12 weeks & $\begin{array}{l}{ }^{b} \text { Alemtuzumab, Flu, } \\
\text { Treosulfan }\end{array}$ & $\mathrm{R}-\mathrm{BM}$ & $4 \mathrm{mo}$ & 12 weeks & alive & failed & no & no & no \\
\hline 9. & $\mathrm{ND}$ & $18 \mathrm{mo}$ & 14 weeks & $\mathrm{Bu}, \mathrm{Cy}, \mathrm{Flu}$ & U-BM & $3 \mathrm{mo}$ & 4 weeks & alive & complete & No data & no & no \\
\hline 10. & ND & $16 \mathrm{mo}$ & 24 weeks & $\mathrm{Bu}, \mathrm{Cy}, \mathrm{ATG}$ & UCB & $5 \mathrm{mo}$ & Yes & alive & failed & no & no & no \\
\hline 11. & $\mathrm{ND}$ & $10 \mathrm{mo}$ & 28 weeks & Bu, Cy, ATG & U-BM & $1.5 \mathrm{mo}$ & Yes & alive & failed & no & no & \\
\hline 12. & A327P, W402X & $11 \mathrm{mo}$ & 4 weeks & $\begin{array}{c}{ }^{b} \text { Campath, Flu, } \\
\text { Melphalan }\end{array}$ & R-PBSC & $3 \mathrm{mo}$ & 6 weeks & alive & complete & no & no & no \\
\hline
\end{tabular}

${ }^{a}$ Age, age at initiation of ERT; ${ }^{b}$ Represents a reduced intensity conditioning regimen.

Abbreviations: ND, not done; mo, months; for donor graft: UCB, unrelated cord blood; U-BM, unrelated bone marrow; R-BM, related donor bone marrow; R-PBMC, related donor peripheral blood stem cells; for preparative regimens: Bu, busulfan; Cy, cyclophosphamide; Flu, fludarabine; TLI, total lymphoid irradiation; ATG, anti-thymocyte globulin; Complete engraftment, $>90 \%$ donor; failed engraftment, $<10 \%$ donor. $4 \mathrm{a}$ and $4 \mathrm{~b}$ represent the two transplants in patient 4 . 
night time oxygen requirement) was noted in 8 of the $12 \mathrm{pa}-$ tients at presentation. Follow-up sleep apnea studies were available in two patients. One child (Patient 1), who demonstrated a sleep study without apnea or hypopnea, showed normal sleep studies when tested after 24 weeks of ERT, and showed similar results when evaluated after HSCT. The second child (Patient 5) showed moderate obstructive sleep apnea at baseline; a repeat study was done 6 months after HSCT, which showed marked improvement. Cardiomyopathy was diagnosed in one patient before initiation of ERT, which resolved after 14 weeks of ERT before HSCT.

\section{Transplant outcomes}

Eleven patients received a single hematopoietic stem cell transplant, and one patient who suffered graft failure after first transplant received two transplants. Preparative regimens, donor source, and transplant outcomes are summarized in Table 1 ; in five patients, a reduced-intensity conditioning regimen was used. The median time to recovery of neutrophil count to $>5 \times 10^{8} / \mathrm{L}$ was 15 days, with a range of 10 to 31 days $(n=10)$. Two of the four transplants with failed donor engraftment were performed using reduced intensity conditioning regimens; this included Patient 4, who subsequently engrafted with donor cells after a second HSCT using a myeloablative preparative regimen.

Two patients developed respiratory failure after HSCT. Patient 2, with an abnormal sleep study before initiation of ERT, manifested respiratory failure 7 days after stem cell infusion, which was diagnosed as a rapid engraftment pulmonary syndrome; the child required ventilator support for 12 days. Patient 4 , who did not have a high-risk respiratory history, required ventilator support 6 days after second HSCT; major post-HSCT complications at time of ventilator support included venoocclusive disease and pulmonary hemorrhage; the patient died 1 month after second HSCT due to multiorgan failure.

\section{DISCUSSION}

HSCT can stabilize long-term neurocognitive function and improve survival in children with Hurler syndrome..$^{2-4,11}$ However, allogeneic HSCT, particularly using unrelated donor grafts, has significant treatment-related morbidity and mortality. Enzyme replacement therapy can significantly reduce abnormal GAG deposits in MPS I; however, as it does not penetrate into the central nervous system, it is not an effective longterm treatment in Hurler children. The rationale for the combined use of ERT and HSCT in Hurler syndrome was based on (1) the high risk of pulmonary complications with HSCT in the early posttransplant period, ${ }^{5,6}$ and (2) the symptomatic benefit of ERT in terms of reducing upper airway obstruction as well as improving lung function in patients with MPS I.,8 This led to the hypothesis that ERT in combination with HSCT may reduce transplant-related complications, particularly pulmonary complications. We present the first mul- ticenter report on the preliminary experience with ERT and HSCT for Hurler syndrome.

In two previous trials of laronidase ERT in MPS I patients, infusion-related toxicity was frequent but typically mild; reactions during subsequent infusions usually became less common and intense by slowing the rate of infusions. ${ }^{78}$ These trials typically involved subjects with less severe clinical phenotypes of MPS I (i.e., Scheie and Hurler-Scheie syndromes), and suggested that antibodies that develop against laronidase are nonneutralizing and do not effect efficacy. ${ }^{12}$ Similar to these data, in our series of 12 patients with Hurler syndrome, infusionassociated reactions were infrequent and mild. Three patients had follow-up data on antibody titers after initiation of ERT; all three developed positive titers against the enzyme. Interestingly, none of these three patients developed hypersensitivity reactions and all showed decline in urine GAG concentration.

When ERT is used in combination with HSCT, a concern (at least theoretical) is with respect to any potential adverse impact of ERT on the donor engraftment. In this series, 4 of the 13 transplants were associated with failure of donor engraftment. Of the three patients who developed positive antibody titers against the enzyme, two showed complete donor engraftment. Due to the different preparative regimes and donor sources used in this series, it is not possible to conclude what effect, if any, pretransplant ERT had on donor engraftment. However, these data are consistent with engraftment results from larger multi-institutional series of HSCT (without ERT) in Hurler syndrome in which donor-derived engraftment varied from $63 \%$ after unrelated donor transplants to $72 \%$ after related donor HSCT. ${ }^{2,3}$

Children with Hurler syndrome are at higher risk for pulmonary and airway related complications, especially in the early period after HSCT. Data from a single center study of 74 children with Hurler syndrome undergoing HSCT showed a $31 \%$ incidence of ventilator intervention and $14 \%$ risk of serious pulmonary hemorrhage in the first 100 days after HSCT. ${ }^{5}$ Another center observed major pulmonary hemorrhage requiring ventilatory support in 3 of 15 children with Hurler syndrome in the first weeks after HSCT. ${ }^{6}$ We speculated that the addition of ERT would decrease the risk of pulmonary complications associated with HSCT. This limited study, however, could not provide sufficient data to determine whether ERT protected the patients from pulmonary complications.

In summary, the data from this multi-institutional series suggest that in children with Hurler syndrome, ERT in combination with HSCT is feasible and relatively safe. The development of antibodies did not affect efficacy of ERT in terms of reduction of urinary GAG concentration. It is hypothesized that ERT in the peritransplant period would reduce the transplant-related morbidity and mortality in children with Hurler syndrome. This initial report, however, was not able to address this issue. To conclusively determine the effect of concomitant ERT on transplant-related outcomes in Hurler syndrome, further study, preferably a multinational, multicenter collaborative study with a standardized protocol is urgently needed. We suggest that this study address the following issues: (1) should 


\section{Grewal et al.}

all patients affected with Hurler syndrome be candidates for ERT before HSCT as compared to HSCT alone; (2) what is the appropriate duration of ERT before transplant, (3) what is the appropriate duration of ERT after stem cell infusion, and should that duration be modified under any specific circumstances (such as in the presence of partial donor engraftment or presence of acute graft vs. host disease); and (4) how can we best evaluate outcomes associated with combined ERT and HSCT, compared to HSCT, alone in patients with Hurler syndrome.

\section{References}

1. Neufeld E, Muenzer J. The mucopolysaccharidoses. In: Scriver CR, Beaudet AL, Sly WS, Valle D, eds. The metabolic and molecular bases of inherited disease. 8th Ed. New York: McGraw-Hill, 2001:3421-3452.

2. Peters C, Balthazor M, Shapiro EG, King RJ, Kollman C, Hegland JD et al. Outcome of unrelated donor bone marrow transplantation in 40 children with Hurler syndrome. Blood 1996;87:4894-4902.

3. Peters C, Shapiro EG, Anderson J, Henslee-Downey PJ, Klemperer MR, Cowan MJ et al. Hurler syndrome: II. Outcome of HLA-genotypically identical sibling and HLA-haploidentical related donor bone marrow transplantation in fifty-four children: The Storage Disease Collaborative Study Group. Blood 1998;91:2601-2608.
4. Staba SL, Escolar ML, Poe M, Kim Y, Martin PL, Szabolcs P et al. Cord-blood transplants from unrelated donors in patients with Hurler's syndrome. N Engl J Med 2004;350:1960-1969.

5. Orchard PJ, Milla CE, Grewal SS, Braunlin EA, Defor TE, Krivit W et al. Determination of high-risk factors in allogeneic transplantation for Hurler syndrome [abstract]. WORLD Lysosomal diseases research network symposium 2004:20.

6. Gassas A, Sung L, Doyle JJ, Clarke JT, Saunders EF. Life-threatening pulmonary hemorrhages post bone marrow transplantation in Hurler syndrome. Report of three cases and review of the literature. Bone Mar Trans 2003;32:213-215.

7. Kakkis ED, Muenzer J, Tiller GE, Waber L, Belmont J, Passage M et al. Enzymereplacement therapy in mucopolysaccharidosis I. N Engl J Med 2001;344:182-188.

8. Wraith JE, Clarke LA, Beck M, Kolodny EH, Pastores GM, Muenzer J et al. Enzyme replacement therapy for mucopolysaccharidosis I: a randomized, double-blinded, placebo-controlled, multinational study of recombinant human alpha-L-iduronidase (laronidase). J Pediatr 2004;144:581-588.

9. Shull RM, Kakkis ED, McEntee MF, Kania SA, Jonas AJ, Neufeld EF. Enzyme replacement in a canine model of Hurler syndrome. Proc Natl Acad Sci USA 1994;91: 12937-12941.

10. Wright J, Motwani J, Gray G, Cooper A, Wraith JE, Lawson S et al. Hurler syndrome (MPS IH): enzyme replacement therapy pre-bone marrow transplantation. $\mathrm{Mol}$ Genet Metabol 2004;81:168-169.

11. Whitley CB, Belani KG, Chang P-N, Summers CG, Blazar BR, Tsai MY et al. Long term outcome of Hurler syndrome following bone marrow transplantation. Am J Med Genet 1993;46:209-218.

12. Kakavanos R, Turner CT, Hopwood JJ, Kakkis ED, Brooks DA. Immune tolerance after long-term enzyme-replacement therapy among patients who have mucopolysaccharidosis I. Lancet 2003;361:1608-1613. 